\title{
My so-called life as a research assistant
}

\author{
Jenna Healey and Terry Crowley
}

This manuscript was prepared for HIST $* 3480$ Workspace Learning under

the supervision of Dr. Terry Crowley, Department of History, College of Arts.

$\mathrm{A}$ s undergraduates, we all cherish our fond memories of summer. We have escaped from the trappings of hectic academic life for four precious months, away from exams and assignments and hours in the library. Yes, when I think back to summer of 2007, I can still remember the heat of the sun beating down on me, a smile on my face as I laid back in my favourite chair, thumbing through the pages of my favourite book - a perfect summer afternoon. Of course, most people don't enjoy the sunshine through the library window, and their favourite book tends not to be a tome of veterinary history - but such was my life as a research assistant.

To be fair, I love libraries, prefer reading to getting a tan and secretly enjoy living among books. But nothing had prepared me for the intensity of a summer full of research. As an Undergraduate Research Assistant for the Department of History, I had been assigned to research the early history of the Ontario Veterinary College for the duration of the summer. I had just finished my second year at the University of Guelph in the Bachelor of Arts and Sciences program with minors in English and Molecular Biology and Genetics. This unique interdisciplinary program had given me a broad enough background to study almost anything. Of course, I had no experience doing history research, and no previous knowledge of the Ontario Veterinary College or veterinary science in general. But that was just part of the fun, and the challenge, of doing this project.

Being an Undergraduate Research Assistant is very similar to being a detective. You have been given an objective - to uncover as much information you can about a subject - and you must go to any means to retrieve this information. Sometimes this will include wandering through libraries for hours, collapsing in defeat between the stacks, carrying copious amounts of books which obscure your vision, and other courageous acts of research. Often you must be stealthy and exploit all the resources available - even if this involves assuming another identity, picking up on the smallest clues left behind and following these leads meticulously. You must be dedicated, you must be tireless, and most importantly you must have an abnormally long attention span. It's a tough job, but some lowly undergraduate has to do it.
In this article, I'll outline some of the trials, tribulations and TRELLIS fun I had during my time as a Undergraduate Researcher Assistant. Along the way I'll relate some amusing anecdotes, and hopefully provide a sense of how challenging - and how rewarding - research can be. As a strong believer in the true interdisciplinary nature of all knowledge, my experiences working for the Department of History can be applied to working within any humanistic or even scientific discipline. The experience of research has its own unique joys and frustrations which I believe are universal, no matter the topic of study.

Beginning the process of research can be a daunting one. As I mentioned before, I had no previous knowledge of the Ontario Veterinary College or anything relating to its history. I started simple - a basic TRELLIS search which produced a dozen results. My initial attitude was that of confidence - I had written term papers with more books than that! I had previously never felt the need to scrupulously record information as I read. I checked the books out of the library, started reading, occasionally writing down important facts when I felt it suited me. Being blessed with a photographic memory, I never had been responsible for recording (a key word) large amounts of specific information about a single subject before. About a week into my research, I felt a rising panic - my sources were blending together, my records were unclear, and I had a million thoughts about the direction I wanted to go next. Most threateningly, I realized that a basic TRELLIS search had only shown me the tip of the iceberg the history of the actual institution was just the beginning. I had to consider the history of veterinary science and the political, social and scientific contexts of the time. If I was to successfully understand the history of this institution, I had to develop a better system. So I collected more sources, took much better notes and critically determined the best course of action. It was time to plunge into the icy depths of this obscure history and reveal the mass of information below the surface.

As I was residing in the GTA, I did a majority of my research at the University of Toronto. To continue the metaphor of research assistant as detective, this is when my 
stealth and resourcefulness came into play. Successful in navigating the subway and city streets, I was confronted with the 14 storey mammoth known as Robarts Library. Accustomed to the six lovely and familiar floors of Guelph's McLaughlin Library, I was at once aghast and delighted with this depository of what seemed like all collected knowledge in the universe. As the third biggest research library in North America, Robarts presented a daunting challenge to the new and inexperienced undergraduate research assistant. After a few rides up and down its frightening narrow escalators, I soon encountered my first major obstacle. Access to the Robarts Library was heavily restricted for all but those associated with the University of Toronto. Although I suspected that I would face some disadvantages as a guest researcher, I didn't quite expect armed security guards at the entrances to the stacks. The wireless internet was password protected, the librarians were cold and unfriendly, and my naïve enthusiasm was crushed under the heavy weight of Robarts' impressive research collections.

I could have remained discouraged, or arranged to pay the fee that would grant me limited privileges as a guest researcher. But instead, as a great detective, I used my cunning to eliminate obstacles in my way. I conveniently (and completely legally) borrowed a University of Toronto electronic identity from a friend who happened to be travelling abroad (I wasn't kidding about assuming alternative identities). Gaining access to the network allowed me to conduct searches of the University of Toronto system. Serendipitously, most of the resources concerning veterinary science and history were exclusively located in Gerstein, the science library which was located elsewhere on campus. Gerstein was much smaller, less intimidating, full of aspiring medical students studying for their MCATs and most importantly fully accessible to anyone who wished to use its resources. I had successfully gained access to a huge wealth of knowledge with only my sense of adventure and academic intuition to guide me.

My starting point was determined by the original history of the Ontario Veterinary College written by Eugene Gattinger in 1962. Even though it soon became apparent that his scholarship was somewhat faulty and contained many gaps, the volume still proved invaluable in identifying useful sources. Starting at the beginning of his reference list, I chose "The Journal and Transactions of the Board of Agriculture of Upper Canada" as my first mission. With a journal name like that, I couldn't help but feel an intense excitement and anticipation. My searches of the University of Toronto catalogue had turned up volumes of the journal from the late 1850 s in the Gerstein library periodical collection, as well as reproductions from the early 1860 s on microfilm in Robarts. I decided to seek out Gerstein's copies first, and after taking a significant chunk of time looking for the library (my sense of direction leaves much to be desired), I arrived to find the periodicals section - under construction and empty.
As an eager and fresh faced research assistant, I was sure that I would be able to navigate the 'temporary storage' that had been provided for the thousands of volumes the library had displaced. After a few inquiries at the desk, I was directed through a plastic curtain into a six-floored, concrete walled space. The floors were semi-transparent, which created a glass floor affect that wasn't quite as amusing as one might expect. The homemade signs indicating the locations of certain journals were scarce and were usually pointing in ambiguous directions. The stairs between floors reminded me of fire escapes, but they were preferable to the elevator, which was of the doorless, self-operated variety. I eventually realized that this journal storage was only for journals from 1965 and onwards, but not before I had gotten myself more than a little lost in the labyrinth of shelves. An older woman approached me, wearing a University of Toronto Libraries ID tag. Relief swept over me - a knowledgeable and wise librarian was here to rescue me. But before I could shower her with thanks, she asked me if I could help her - find a way out! Together, we retraced our steps until we found the exit back into the library - though it wasn't until later that I truly appreciated the irony and humour of the situation.

I didn't let a little misdirection discourage me (which is a good thing considering how many times I got lost during this four month period). I headed down to "Three Below", Gerstein's name for the third (and final) basement floor, where all the journals pre-1865 were actually being stored. Although there was only one floor to contend with this time, I had the new experience of operating manual moving shelves. I probably would have had some anxiety about being trapped between a few of them, if there had of been anyone else there. But considering it was a mid-week afternoon in May, the place was deserted. I could only hope that if a large pile of books happened to fall on me, someone would eventually find me sprawled between the stacks. The journals were arranged alphabetically, which seemed like it would be simple enough to navigate - yet another naïve assumption of the fresh-faced research assistant. After half an hour of searching in vain, the "Journal and Transactions of the Board of Agriculture of Upper Canada" could not be found under any variation of its name. I looked under 'Transactions', 'Board of Agriculture', 'The Canada Farmer' (an alternate name), even 'Upper Canada'. I felt defeated, and I was forced to turn to my only source of help - the librarian. This was the beginning of my realization that a librarian is a research assistant's best friend and resource the Watson to my academic Sherlock Holmes.

The librarian was similarly puzzled, until he pulled out a large tome filled with almost ancient journal indexes. The apparently obvious fact that I had been missing is that the journal was filed under Ontario - Board of Agriculture, since it was the precursor of that organization. How could I have possibly overlooked such a simple fact? I followed my new 
lead all the way back down to the basement. My excitement soon dissolved when the lead turned out to be just another red herring. The "Journal and Transactions of the Board of Agriculture of Upper Canada" was no where to be found under the heading of 'Ontario'. Defeated once more, I slumped against one of the large bookcases, face to face with a large box labelled 'Ontario Veterinary College'. After rubbing my weary research assistant eyes, I was delighted by this serendipitous coincidence - I had discovered original copies of the college's Annual Announcements, including the very first one from 1875! Although I would eventually learn that Guelph already held copies of all these announcements in their Ontario Veterinary College Collection, it made me feel a lot better than day to not go home empty handed.

This eventful first day of library adventures taught me many things that I would carry with me throughout the summer. First of all, asking for help is often the smartest and quickest way to find what you're looking for. Secondly, computerized library catalogues are not perfect - I still can't find any record of the University of Toronto holding those original Annual Announcements. Locations of documents have moved without any record of where they've gone, volumes mysteriously go missing, and some valuable items just aren't catalogued at all. At lastly, really old documents tend to be fragile and you have to be very careful when you're photocopying them - believe me.

My experience with the Annual Announcements was the first in a long series of discoveries which I celebrated as unique - until I realized that they had already been documented in the existing literature. Although it was my job only to retrieve and synthesize as much information as possible, I secretly desired to hit the historical jackpot in some way - uncover something new and exciting that no one else had found before. Going into the job, I had an idealized view of what history research would be like - thumbing through musty old diaries, gazing at yellowed photographs, piecing together the lives of those long deceased, excavating long buried treasures... you get the (completely inaccurate) picture. Instead, what I have discovered is most historical documents have been transferred to microform and that old letters are more frustrating than romantic considering Andrew Smith's (founder of the Ontario Veterinary College) illegible handwriting. It actually took me the better part of an afternoon to decipher a three page letter - that's the last time I'll fantasize about historical documents.

Slowly but surely I began to develop the skill set of a good research assistant. I meticulously recorded all my references in proper Chicago form (being at the time ignorant of the usefulness of an electronic referencing program). I developed a system of what I called "leap-frogging". I would pour over a list of references from an already retrieved source to identify others which would be useful to me, and then added them to the list of what to retrieve next. Often these searches would be fruitless, but sometimes they would turn up a valuable document which I hadn't uncovered in my own explorations. Even as the summer progressed I would still glance over the references and uncover a source that had been right under my nose all along. I began to know the names of the authors who published in this area by heart not that difficult considering that Canadian veterinary history is a narrow area of focus. I found myself smiling in recognition when I came across a familiar name. Their recognizable writing styles and extensive research brought me comfort during the long days (libraries in the summer can get lonely).

Now I don't want to brag, but my microfilming skills can probably rival that of any research assistant at this school. I operated every single type of microform and microfilm machine you can imagine. I memorized error codes in University of Toronto's electronic readers, and reminded the librarians how to fix them. For example, an L9 error involves the very scientific unlocking of the printer and vigorous shaking of the toner, followed by prompt replacement of the toner - this is invaluable information. I can fix any jam, focus any quality of film, and crop like nobody's business. I spent many long hours at the University of Toronto's Media Commons, an impressive over air-conditioned room full of other dedicated research assistants. Employees gave me sympathetic looks when they handed me large stacks of Canadian agricultural journals or Andrew Smith's original class notes. Required to identify my home institution on the retrieval slip, I was subject to daily comments about how 'funny' it was that I was from Guelph and I was researching veterinary history - what a coincidence! After the fifth day of such a comment, I smiled mildly and commented that the Ontario Veterinary College was actually located in Toronto until 1922, so it was really more appropriate that I was researching at $\mathrm{U}$ of $\mathrm{T}$. I'm not sure if the employee truly appreciated my efforts to enlighten them, but I was just passionate about my topic of research. I've also got photocopying down to an exact science. I soon realized that only inexperienced research assistants actually use the lid on the photocopier. It's not really there to protect your vision, just to hamper the process of your copying. As long as you don't look directly at the bright flashes, your eyes can adjust quite nicely. I developed an assembly line system which maximized the number of pages copied per second. I can still recall looking down a line of photocopiers at $\mathrm{U}$ of $\mathrm{T}$, research assistants photocopying robotically, blue flashes permeating the air - the efficiency was truly inspiring.

After a while, I became assimilated into what I like to call the 'library culture'. A large part of this culture includes the excessive consumption of coffee and similar caffeinated beverages. Within and around the area of the library, there are easily more than a dozen Starbucks, Tim Hortons, Second Cups and independent coffee shops. This provides the necessary variety for 'research breaks' throughout the day, which I will admit I took advantage of. I also developed the habit of watching the regulars in the library and making 
note of their idiosyncratic habits. On the fifth floor of the government stacks there was the man who consistently paced around the same three tables, spent a few minutes consecutively staring at me and other patrons, before returning to an enormous government document that he would read intensely before starting the same process over and over. A professor type who consistently ate lunch in the cafeteria would silently mouth the words to his newspaper, everyday a varying amount of dust covering his clothing from biking to work. There were many desperate looking students around my age studying for various professional exams, and the occasional research assistant or grad student (I can only assume) looking consistently bored. I developed a bad habit of purchasing used books at lunch time, but I justified it as necessary reading for the subway ride home. Unfortunately, I cannot similarly justify the occasional purchase of shoes made while window-shopping on my lunch break.

However, the job is not all always as glamorous as I have made it out to be. There are numerous frustrations and difficulties that are inherent in being a research assistant that one must take in stride. As I have already alluded to, sometimes a source whose location seems very straightforward is impossible to find. Despite my best intentions, sometimes I felt that I would waste days searching or perusing sources that didn't seem to be of any use. When days were long, hitting a single roadblock can end your streak of productivity. One of my tasks was to retrieve, search and photocopy all useful parts of the Sessional Reports of the Province of Ontario as it pertained to the Ontario Veterinary College. About thirty years in, the reports which annually appeared in the papers disappeared. I put on my detective hat, formulated hypotheses as to where the paper trail may continue and followed my instincts but to no avail - the paper trail would not be picked up. I spent the rest of the afternoon in vain following through with every possible location of the reports until I had to accept that they were not to be found. Such a failure is a blow to the confidence of the research assistant who had felt confident that they could crack any case. There were days when finding useful information was like finding water in the desert. On other days, you collect so much material that you dread how much photocopying you'll have to do. One such day at the Ontario Veterinary College library, I literally ran into a bookshelf because the pile of books I was carrying extended above my line of vision. I had quite literally turned into the caricature of a true library dweller. And don't ever let anyone imply that a research assistant isn't a physical job - lifting those books was better than a gym membership (almost).

Research also takes focus and dedication to single subject on a scale that I was certainly not used to. During the year, it is almost impossible to focus solely on one course for too long before another puts demands on your attention.
Research papers usually get truncated around twenty pages, and are soon forgotten after they are handed in. As a student used to studying a wide variety of topics, I won't deny that some days I had to force myself to focus on the subject at hand. A unique challenge of being a research assistant during the summer months is that when the weather is beautiful and everyone is frolicking outside, it's difficult being on the other side on the library window. I tried working outside on some days - but after one really bad sunburn and some serious eye strain (computer screens and sunlight do not go together), I decided against it. But in defence of the job, there is something incredibly rewarding about dedicating all of your energy to one thing. Being a perfectionist, this was the ideal job for me to follow up on all the impulses that I normally have to suppress during the semester. I could take my time and read the entirety of books, and if I liked I could go back and read them again. I could delete and rewrite pages of my paper without worrying about the due date. Of course this slowed down my process, but I found that this intense focus allowed time for these kinds of obsessions.

About a month into the job I started developing a faint sense of pride that I was acquiring a level of knowledge about my topic that was uncommon among most people, even historians. In a way, it was gratifying to develop an intense understanding about one period of history. In other ways, I felt isolated to be the only one in my immediate social sphere with an invested interest in the early history of the Ontario Veterinary College. I subjected my friends and family to all sorts of stories anyway, attempting to transfer onto them my new found passion for veterinary history. I was somewhat unsuccessful, but it prevented veterinary history from becoming the all consuming focus of my life.

About two months in, the (relatively) carefree days of researching were over, and it was time to write a paper on what I had found. This transition was probably the hardest part of the summer. One thing I had to accept about doing research is that it is a perpetually unresolved process. There are always more sources to find, more books to read, new leads to follow. But at some point I just had to take the immense amount of information I had and sort through it. My biggest challenge was how to synthesize the wealth of sources and perspectives I had acquired into something comprehensive. The history of the Ontario Veterinary College was interesting in that there were multiple interpretations that I could have gone with, and in beginning the paper I changed my interpretation several times. However, once the pen was to the paper (and by this I mean my fingers to the computer keys), the writing wasn't as painful as one might expect. Referencing was timeconsuming, and it took much of my concentration to avoid slipping back into researching mode. It was a slow process, but a gratifying one. It felt nice to watch the number of pages increase as I expressed the thoughts, ideas and knowledge that had been clogging my mind since May. Never before 
had I invested so much time and energy into one single project, and it was both simultaneously exhausting and exciting.

The one thing I would like to impart to my fellow undergraduates is that the process of research is exciting, frustrating but ultimately so rewarding. Research done in most undergraduate classes is transient - enough to complete a paper and move onto the next task. But assisting with a true research project involves an investment and commitment that is much beyond anything expected of me before. I was often frustrated, I struggled to keep focus, and at times I felt like I was drowning in a deep sea of sources. But eventually I learned to make my way. But being a true detective, I picked up on clues, identified likely suspects, figured out their motives. I was able to take everything I had found and write an exhaustive and comprehensive paper. By the end of the summer (and even now three months later) I have a lot of difficulty letting this job go. So much of my time invested into a single thing makes me feel like I have a huge stake in the future of this information. I want it to be recorded for future readers and its significance appreciated. If I wasn't forced to stop, I would perpetually be reinterpreting my sources, adding new perspectives to my paper, widening the scope of my research. Of course, it also felt very satisfying to finally paper clip that paper together (since no stapler would stand up to its girth), knowing that I had accomplished something in my summer months - even if it was only important to me and my supervisor.
So would I recommend a position as an Undergraduate Researcher Assistant to my fellow undergraduates? If one has any interest in research or an academic career, it is an invaluable experience. It is not only valuable for your Graduate School applications, or as a source of summer income. For me, this job was a major learning experience which will aid me in all my future academic endeavours.

My research skills alone have seen a ten fold increase. I have learned how to access a variety of sources, navigate library systems and organize large amounts of information. The process of writing was draining but I am confident that it helped to improve my skills. Although the topic of research is not something I am personally interested in pursuing history of veterinary science will never be my true passion - I don't think this mattered in terms of the experience I had. As undergraduates, our learning is all too often hurried. In the midst of essay deadlines and downtown excursions, our semesters become frantic and true learning experiences are often pushed aside. I was so grateful to get a true idea of what real research is like, and I am honoured that I was allowed to participate in the process. I most certainly have developed an appreciation for professors and academics everywhere - their job is not as easy as it seems. And as long as there are hard working academics conducting research, there will be undergraduates there to do some of the detective work - working tirelessly until the case is closed. 